\title{
Modifications and Frequency Occurrence of Gestures in NS - NS and NNS - NS Dyads
}

\author{
Juliana Wijaya
}

\begin{abstract}
In this study, I investigate cross-linguistic differences and similarities in the speech associated gesture in the NS (Native Speaker) - NS and NNS (Nonnative Speaker) - NS dyads when they are telling a narrative. The gesture production between Indonesian native speakers when communicating in Indonesian (L1) and in English (L2) was coded and assessed based on Mc.Neill's model of overall gesture units. The Indonesian speakers' gesture modification when interacting in English was measured by the size of the gestures. The results indicate that Indonesian native speakers gesture more when they communicate in English and modify their gestures by making them bigger and therefore more noticeable to their interlocutors. They use gestures as a communication strategy to help interlocutors comprehend their idea.
\end{abstract}

Keywords: Beats, Clarification request, Communication breakdown, Communication strategy, Comprehension check, Conformation check, Deictics, Emblems, Gesture modification, Gesture units (G-units), Iconics, Lexical access, Metaphorics, Speechassociated gesture

This study investigates cross-linguistic differences and similarities in the speechassociated gesture, or merely gesture (to denote those hand movements that accompany spontaneous speech) in the NS (Native Speaker) - NS and NNS (Nonnative Speaker) - NS dyads when they are telling a narrative. There have been many studies in the interaction of NS - NNS in SLA (Second Language Acquisition) (Long, 1981, 1983; Long \& Sato, 1983; Pica 1984), which claim that NSs modify their input when interacting with nonnative speakers. Their modifications include shorter and simple sentences, repetition and restatements, high frequency vocabulary, avoidance of low frequency vocabulary and sentence structures, limited use of pronouns, and restricted topics (such as topics about NNSs' experiences and plans). NSs also tend to speak slower and louder and their utterances are sometimes high in pitch. When communication breakdowns occur between NS-NNS, they have to negotiate to restore the meaning because NSs usually request clarification/ conformation so that NNSs have to modify and restructure the interaction. Confirmation, comprehension check and clarification request 1 are communication strategies that assist language comprehension and production during communication breakdowns (Pica, 1984). On the other hand, NNSs also employ communication strategy to express meaning when they face communication problem in the second language (Bialystock, 1990). The communication strategy is employed even more when the NNs have a limited command of the second language. They may have to make up for a lack of knowledge of L2 (second language) grammar or vocabulary. The use of paraphrase, mime and gesture typically characterizes this strategy.

People often gesture when their speech is failing in some way. In this case, gesture is used to assist language comprehension and production. People frequently 
gesture to retrieve elusive words from memory (Goodwin \& Goodwin, 1986) and to add emphasis as well. The relationship between gesture and language is essential in gesture research. Gestures function more than just to replace lexical items. Goodwin (cited in Kendon 1986) points out that people in face-to face interaction gain much information from one another by observing as well as listening. Kendon (1986) claims that interlocutors attend to some gestures and disattend or ignore some others. McNeill (1997) proposes that gestures occur when new elements are introduced in the discourse.

In relation to SLA, one of the essential questions is do people modify their gestures when they communicate in their L2? A few studies have investigated the use of gestures in SLA even though gestures play a big role in communication. Kita (1993) found that balanced English-Japanese bilinguals gesture differently from unbalanced ones in depicting certain motion verbs which do not exist in Japanese. Gullberg's study (1998) indicates that language learners use more gestures in L2 than in L1 (first language) production. Based on Gullberg's model, this study is conducted to observe whether Indonesians use more gestures and modify their gesture when communicating in English.

\section{Overview on Speech-Associated Gestures}

According to Kendon (1986) gestures may be independent of speech and serve as a complete utterance by themselves. This type of gesture is autonomous, and is mostly referred as emblem. Emblem replaces lexical items. For example, in some cultures, people nod to show agreement, and index and middle fingers forming $\mathrm{V}$ indicates victory. Gestures may as well occur in conjunction with speech. This type of gesture is referred to as speech-associated gestures (this study focuses more on this type of gesture). This speech-associated gesture is called by different names, namely 'gesticulation' (Kendon) or 'gestures' (McNeill) or 'illustrator' (Ekman, 1977, cited in Kendon 1986). This study, however, uses McNeill's term 'gesture' to account for all speech-associated gestures.

Four types of speech-associated gestures according to McNeill are as follows:

1. Iconics bears a close formal relationship to the semantic content of the speech.

2. Metaphorics present an image of abstract concept. There is 'base' (which is the concrete entity or action that is actually presented in the gesture), and 'referent' (the concept itself).

3. Deictics are pointing movements.

4. Beats are movements that do not present a discernible meaning.

According to Mc.Neill (1992), in communication, verbal part of communication is transformed into propositions (propositional structure, Kendon, 1986) while imagistic part is transformed into a sketch (image-like structure, Kendon, 1986). Imagistic information from working memory is expressed in an iconic gesture. Kendon (1986) points out that iconic gestures vary cross culturally. Gestures can cross culturally vary because they can be learned as a communication system.

McNeill distinguishes iconic from metaphoric gestures. But, de Ruiter (In press) treats metaphoric gestures as iconics, because according to him from the perspective of gesture production it is of no relevance whether the imagery underlying the gesture is related to abstract or real entities. I also find that the line between iconic 
and metaphoric is a bit fuzzy. Gestures expressing the rhythmic structure of speech are referred to as beats (McNeill) or baton (Ekman).

Gestures representing spatial information coded as deictics help comprehension as well. According to Ruiter (In press) pointing gestures accompanying deictic expression function to enhance the quality of the communication. Morrel-Samuels and Krauss (1992, p. 616) claim that "unlike most speech-related gestures, deictic gestures are likely to convey more information than their lexical affiliates (e.g., saying this one without pointing can be far less informative than pointing and saying nothing)." During communication, the frequency occurrence of deictic gestures is also very high.

Gesture production is also strongly related to lexical access. Krauss et. al. (1991) claim that in communications breakdown gestures help resolve the problem by facilitating the lexical search process. Furthermore, Krauss et. al. and Rimè and Schiaratura (1991, cited in Kendon 1994) are skeptical of the idea that speechassociated gestures have communicative functions. Rimè and Schiaratura especially argue that speech-associated gestures occur not for the benefit of interlocutors, but they merely facilitate the process of verbal encoding. Rimè, Schiaratura and Krauss seem to agree that speech-associated gestures have only incidental communicative function. On the other hand, Kendon (1994) and McNeill (1992) confirm that speechassociated gestures produced by speakers have a communicative function, and they affect recipients. Speech-associated gestures affect the interpretation of speech utterances. Pederson (personal communication) also argues against Krauss' notion that gesture is merely used for lexical access based on the fact that there are some variations in gesture cross-culturally which is not possible if gesture is used for lexical access only.

\section{Research questions}

This research is a pilot project of gesture study in SLA involving few Indonesian and English native speakers. The speakers do not represent the whole group of English non-native speakers. With regards to size, when communicating, Indonesians seem to gesture less and gesture smaller than Americans, who involve more gestures and bigger hand-movements to express their thoughts (empirical research has to be conducted to observe these special features). This study aims to answer the following research questions.

1. Do Indonesian native speakers use more gestures when communicating in English than in Indonesian? (The amount of gesture is determined by the frequency occurrence of gestures in L1 and L2 by looking at the overall gesture units or Gunits (Mc.Neill, 1992).

2. Do Indonesian native speakers (INS) modify their gestures when they communicate in English? (The modification is measured by the size of the gestures).

\section{Hypotheses}

1. Gesture is expected to occur more frequently when an INS is communicating in English because the locutor has to retrieve the lexicons, solicit the lexicons, negotiate the meanings (negotiated interactions) and retrieve the story itself 
(memory). Additionally, the interlocutor will promote more gestures to occur by giving feedback (positive evidence, negative evidence in forms of error correction, conformation check, clarification request, etc).

2. Gesture is expected to occur less frequently when INS is communicating in Indonesian because the locutor most of the time does not have difficulty in retrieving the lexicons or soliciting them from the interlocutor. She does not need to negotiate the meanings either. In this case, gesture is expected to occur when the locutor has to retrieve the story (memory) or when she wants to emphasize.

(Note: Emphasis might make the gesture bigger in size but does not trigger a higher frequency.)

3. There will be some differences in the gesture in the NS-NS and NNS-NS dyads due to the complexity of the L2. INSs are expected to modify their gestures in NNS-NS dyad.

\section{Method}

\section{a. Subjects}

There were six subjects involved in this study. They were four Indonesian native speakers (2 University of Oregon students, 1 housewife, and 1 visiting scholar at the University of Oregon), and two English native speakers (1 University of Oregon student, and 1 University of Oregon administrator). The Indonesian students' gesture production was the one coded and assessed for the purpose of this study. They had similar English proficiency level (their TOEFL scores were 547), and both of them had been living in the states for less than half a year prior to the experiment. All of the subjects were female, and they did not know each other prior to the experiments.

\section{b. Material}

The stimulus cartoon is Boboscript used in Marianne Gullberg's Ph.D thesis (1998). The cartoon is about a patient who needed to get some medicine prescribed by her doctor. However, the pharmacists could not read the prescription because it had been badly written. The patient took the prescription back to her doctor who finally used his foot to write a new prescription, and his footwriting turned out to be more readable than his handwriting.

I considered using this cartoon because no emblematic gestures (e.g. index finger and middle finger forming $\mathrm{V}$ to indicate victory) are expected to occur. It is possible for the difficulty in the lexical access to occur in both L1 and L2 because it deals with unfamiliar (less frequent) terminology such as pharmacy, and pharmacist. The cartoon also permits a lot of spatial references to occur because it has many types of entities that the interlocutor has to put in the discourse. Moreover, there is no written-text (verbal message) in the cartoon so that linguistic structures and certain lexicons are not imposed on the locutor in both L1 and L2, and the locutor has to find her own way to communicate the story.

\section{c. Procedure}

Two subjects were asked to tell a narrative in L1 and L2. They were shown the printed cartoon 'Boboscript', and were asked to understand the pictures and memorize the story. Then they were required to tell the story in Indonesian to an Indonesian native speaker and in English to an English native speaker. The 
storyteller was asked to tell and retell the story to different interlocutors carefully enough for the listener to be able to retell it in her turn, so the interlocutor had to understand the story completely. In each individual experiment the primary subjects (the interlocutors) had the following steps:
- step 1 : INS1 - INS3
(L1)
: INS1 - ENS1
- $\quad$ step 2 : INS2 - ENS2
INS2 - INS4

Note: INS = Indonesian native speaker, ENS = English native speaker .

After each story telling, the original listeners retold the story to the 'audience' (camera). The previously mentioned steps were made to avoid the effect of order in statistical analysis. The narratives were videotaped, transcribed and coded for gesture using the following gesture categories (McNeill, 1992): iconics, metaphorics, deictics and beats. Each gesture except beat (i.e., "formless hands that convey no information but move in rhythmic relationship to speech", McNeill, 1992, p. 377) is counted as one G-unit (which includes 'preparation-stroke-retraction' or 'pre-stroke, post-stroke and retraction'). The gestures counted in this study are the ones involve the movements of the fingers, hands and arms only. I counted gesture units per clause (McNeill, 1992) and gesture sizes. Gesture size is based on the Indonesian native speakers' base line. The gestures that involve the movement of the fingers and hands only are considered small and the ones involved the movement of arm and elbow are considered big.

\section{Results}

The results of the study are summarized in the following simple descriptive statistics tables. Since there was an extremely limited number of subjects involved, a very simple descriptive statistic is used to analyze the collected data.

Table A. Means Occurrence of Gestures Including Iconic, Metaphoric and Deictic per clause.

\begin{tabular}{|l|l|l|}
\hline Subject & Indonesian & English \\
\hline INS1 & 0.15 & 0.34 \\
\hline INS2 & 0.46 & 0.63 \\
\hline Average & 0.31 & 0.49 \\
\hline
\end{tabular}

Table B. Proportion of Big and Small Gestures per clause

\begin{tabular}{|l|l|l|l|l|}
\hline Subject & \multicolumn{2}{|c|}{ Big Gesture } & \multicolumn{2}{c|}{ Small Gesture } \\
\hline Language & Indonesian & English & Indonesian & English \\
\hline INS1 & 0.33 & 0.55 & 0.67 & 0.45 \\
\hline INS2 & 0.42 & 0.45 & 0.58 & 0.56 \\
\hline Average & 0.38 & 0.5 & 0.63 & 0.51 \\
\hline
\end{tabular}

Table C. Proportion of Each Gesture Category per clause

\begin{tabular}{|l|l|l|l|l|l|l|}
\hline Subject & \multicolumn{2}{|c|}{ Iconic } & \multicolumn{2}{c|}{ Deictic } & \multicolumn{2}{c|}{ Metaphoric } \\
\hline & Indo & English & Indo & English & Indo & English \\
\hline INS1 & 0.56 & 0.45 & 0.44 & 0.5 & 0 & 0.05 \\
\hline INS2 & 0.27 & 0.14 & 0.73 & 0.86 & 0 & 0 \\
\hline & 0.42 & 0.3 & 0.59 & 0.68 & 0 & 0.03 \\
\hline
\end{tabular}


Table D. Proportion of Beats per clause

\begin{tabular}{|l|l|l|}
\hline Subject & Indonesian & English \\
\hline INS1 & 0.7 & 0.49 \\
\hline INS2 & 0.32 & 0.35 \\
\hline Average & 0.51 & 0.42 \\
\hline
\end{tabular}

\section{Discussion}

Since a very limited number of subjects was involved in this preliminary study, I cannot determine whether there are significant differences between the results of the proportion of the gesture in the NS-NS and NNS-NS dyads. However, table A shows that Indonesian native speakers tend to gesture more when communicating in English. This tends to support hypothesis 1 that the gesture would occur more frequent when people speak in their L2. However in this experiment, the previously mentioned negotiation of meaning did not occur as much as expected. It occurred only a few times in NNS-NS dyad, and they were mostly initiated by the English native speakers .

1. ENS2: They \# they were all pharmacists? (clarification request)

INS2 : Ya. They were all pharmacists, and after ....

2. ENS2: Feet? (clarification check)

INS2 : Ya

ENS2: Feet. (conformation check)

INS2 : Foot \# foot writing.

ENS2: Foot writing.

INS2: Iya.

ENS2: (laughing) OK.

Communication breakdowns did not occur frequently either. Only when the subjects could not remember the word prescription and pharmacy and solicited them from the interlocutors did this communication breakdown occurred. Gesture accompanying this speech, however, can be interpreted either as a lexical access process or word solicitation from the interlocutor.

3. INS1: $[<u h>\text { what's the thing }<\text { uh }>\text { recip.... }]^{2}$

O-VPT iconic: hands raised, two index fingers draw a square in the gesture space

Form: B

ENS1: A prescription

4. INS2: ... and when she [get there she give the \# what]

$\mathrm{O}-\mathrm{VPT}$ deictic: finger pointing to left, right and left

Form: B

ENS2: Pharmacy

Compared to the other types of gestures, deictics occurred the most because of the task, which involves many concrete entities: the patient, three pharmacists, the nurse, and the doctor. The locutors felt the need to put the image-like entities in a gesture space. They reconstruct a scene with objects in it, and refer to them with deictic gestures.

5. INS1 : [she's talking to the nurse]

O-VPT deictic: pointing left to she and right to the nurse

Form: S

6. INS2 : they returned the recipe to the patient] and [the patient go back to the doctor] 
10.INS1 : ... yang apotekernya \# yang tukang campur obat [who is the pharmacist, the one who mixes the medicine] 


\section{Beat accompanied the word 'tukang campur obat'}

It is also possible that beats are used for emphasis. But emphasis is usually marked by the size of gestures (usually happens in NS-NS dyads), which did not occur in this study. When the subjects were in NS-NS dyads, they tend to use smaller gestures. This can be caused by social distance and can also cultural specific as well. It seems that Indonesian females (Note: the subjects were all female to avoid gender effect) do not gesture that much, and if they do, they keep it small. Interestingly, they use bigger gesture when interacting in L2, suggesting that in L2 they want to make their gestures more noticeable to the interlocutors. In that way, gestures can be regarded as communication strategy, and different contexts and conditions contribute to the frequency and sizes of gestures.

\section{Conclusion}

The results of this study indicate that Indonesian native speakers gesture more when they communicate in L2 (English), and modify their gestures by making them bigger and therefore more noticeable to their interlocutors. This is consistent with the notion that gestures are also used as a communication strategy to help interlocutors comprehend their idea. Indonesian native speakers, in this study also tend to gesture less and or gesture small when communicating with other Indonesian native speakers. Furthermore, with more subjects from different length of exposure and different L2 proficiency levels involved, this study would have a more telling result. The length of exposure and the proficiency of L2 may influence the occurrence and form (size) of gestures. It would also be interesting to compare how English native speakers modify their gestures when communicating with nonnative speakers to observe how gestures are employed as communication strategy in native speakers non-native speakers' interaction.

\section{References}

Bialystok, E. (1990). Communication strategies. Oxford: Basil Blackwell.

De Ruiter, Jan P. (In press). The production of gesture and speech. In D. McNeill (Ed) Language and gesture: Window into thought and action.

Ekman, P. \& Wallace, F. (1969). The repertoire of non-verbal behavior: Categories, origins, usage and coding. Semiotica 1 (1), 49-68.

Goodwin, M. H. \& Goodwin C. (1986). Gesture and coparticipation in the activity of searching for a word. Semiotica 62 (1/2), 51-75.

Kendon, A. (1986). Some reasons for studying gesture. Semiotica 62 (1/2), 3-28.

Kendon, A. (1988). Sign languages of aboriginal Australia: Cultural, semiotic, and communicative perspectives. Cambridge: Cambridge University Press.

Kendon, A. (1994). Do gestures communicate? a review. Research on language and social interaction, 27 (3), 175-200.

Kita, S. (1993). Speaking processes in balanced and unbalanced Japanese-English bilinguals: Evidence from spontaneous gestures that accompany speech. Ph.D.thesis, Linguistcis/Psychology, University of Chicago, Chicago. 
Krauss, R.M. Morrel-Samuels, P. \& Colasante, C. (1991). Do conversational hand gestures communicate? Journal of personality and social psychology, 61 (5), 743754.

Long, M. (1983). Native speaker/non-native speaker conversation and the negotiation of comprehensible input. Applied linguistics, 42, 126-141.

Long, M. \& Sato, C. (1983). Classroom foreigner talk discourse: Forms and functions of teachers' questions. In H. Seliger \& M. Long (Eds.), Classroom oriented research in second language acquisition, pp. 268-285.

Long, M. (1981). Questions in foreigner talk discourse. Language learning, 31 (1), 135-138.

McNeill, D. (1992). Hand and mind. Chicago: Chicago University Press.

McNeill, D. (1997). Growth points cross-linguistically. In J. Nuyts \& E. Pederson (Eds.), Language and conceptualization, (pp. 190-212). Cambridge: Cambridge University Press.

Morrel-Samuels, P. \& Robert M. K. (1992). Word familiarity predicts temporal asynchrony of hand gestures and speech. Journal of experimental psychology: learning, memory and cognition, 18 (3) 615-622.

Pica, T. (1984). Second-language acquisition, social interaction, and the classroom. Applied Linguistics, 8, 3-21.

1 a. Conformation checks involve NSs' expressions including part or complete repetitions of the NNSs' previous utterances with rising intonation and questions which elicit confirmation from the NNSs that the NSs understood the NNSs' previous utterances correctly. NSs expect 'Yes' answer. e.g. NNS : She did it carefully.

NS : Carefully? (with rising intonation)

NNS : Yes, carefully.

b. Comprehension checks involve NSs' expressions (typically tag questions, repetitions with rising intonation or utterances like 'Do you understand?', 'All right?', 'OK?') which check comprehension by the NNSs.

c. Clarification requests involve NS's expressions, usually questions that consist of Yes/No or WHquestions (e.g. What do you mean?), rising intonation questions and tag questions, which require NNs to furnish new information or recode information previously given.

2. The gesture coding is taken from McNeill (1992). The conventions are as follows:

[...] stroke phase of gesture

(...) notes and translation

\# unfilled pause

$<\ldots>$ filled pause with duration in seconds

O-VPT observer viewpoint of iconic gesture

Comments are in boldface.

Additional coding for form of gesture in this study

$\mathrm{B} \quad$ big gesture (involves arms and elbows)

S small gesture (involves only fingers and hands) 